\title{
Precise aftershock distribution of the 2011 off the Pacific coast of Tohoku Earthquake revealed by an ocean-bottom seismometer network
}

\author{
Masanao Shinohara ${ }^{1}$, Yuya Machida ${ }^{1}$, Tomoaki Yamada ${ }^{1}$, Kazuo Nakahigashi ${ }^{1}$, Takashi Shinbo ${ }^{1}$, Kimihiro Mochizuki ${ }^{1}$, \\ Yoshio Murai $^{2}$, Ryota Hino ${ }^{3}$, Yoshihiro Ito ${ }^{3}$, Toshinori Sato ${ }^{4}$, Hajime Shiobara ${ }^{1}$, Kenji Uehira ${ }^{5 *}$, Hiroshi Yakiwara ${ }^{6}$, \\ Koichiro Obana ${ }^{7}$, Narumi Takahashi ${ }^{7}$, Shuichi Kodaira ${ }^{7}$, Kenji Hirata ${ }^{8}$, Hiroaki Tsushima ${ }^{8}$, and Takaya Iwasaki ${ }^{1}$ \\ ${ }^{1}$ Earthquake Research Institute, University of Tokyo, Tokyo 113-0032, Japan \\ ${ }^{2}$ Institute of Seismology and Volcanology, Hokkaido University, Sapporo 060-0810, Japan \\ ${ }^{3}$ Graduate School of Science, Tohoku University, Sendai 980-8578, Japan \\ ${ }^{4}$ Graduate School of Science, Chiba University, Chiba 263-8522, Japan \\ ${ }^{5}$ Institute of Seismology and Volcanology, Kyushu University, Shimabara 855-0843, Japan \\ ${ }^{6}$ Faculty of Science, Kagoshima University, Kagoshima 892-0871, Japan \\ ${ }^{7}$ Japan Agency for Marine-Earth Science and Technology, Yokosuka 237-0061, Japan \\ ${ }^{8}$ Meteorological Research Institute, Japan Meteorological Agency, Tsukuba 305-0052, Japan
}

(Received February 3, 2012; Revised August 25, 2012; Accepted September 5, 2012; Online published January 28, 2013)

\begin{abstract}
The 2011 off the Pacific coast of Tohoku Earthquake occurred at the plate boundary between the Pacific plate and the landward plate on March 11, 2011, and had a magnitude of 9. Many aftershocks occurred following the mainshock. Obtaining a precise aftershock distribution is important for understanding the mechanism of earthquake generation. In order to study the aftershock activity of this event, we carried out extensive seafloor aftershock observations using more than 100 ocean-bottom seismometers just after the mainshock. A precise aftershock distribution for approximately three months over the whole source area was obtained from the observations. The aftershocks form a plane dipping landward over the whole area, nevertheless the epicenter distribution is not uniform. Comparing seismic velocity structures, there is no aftershock along the plate boundary where a large slip during the mainshock is estimated. Activity of aftershocks in the landward plate in the source region was high and normal fault-type, and strike-slip-type, mechanisms are dominant. Within the subducting oceanic plate, most earthquakes have also a normal fault-type, or strike-slip-type, mechanism. The stress fields in and around the source region change as a result of the mainshock.
\end{abstract}

Key words: The 2011 off the Pacific coast of Tohoku Earthquake, aftershock, focal mechanism, seismicity, ocean-bottom seismometer (OBS).

\section{Introduction}

The 2011 off the Pacific coast of Tohoku Earthquake is one of the largest earthquakes to have occurred near the Japan islands in the historical record. The Japan Meteorological Agency (JMA) reported that the epicenter was positioned off Miyagi and the magnitude of the earthquake reached 9.0. Because the focal mechanism of the mainshock relates to the relative motion of the subducting $\mathrm{Pa}-$ cific plate and the overriding landward plate, the 2011 earthquake occurred at the plate boundary between the subducting Pacific plate and the landward plate (e.g. Nettles et al., 2011). Teleseismic data from the mainshock revealed that the source region of the earthquake spread over a width of approximately $500 \mathrm{~km}$ (e.g. Yagi and Fukahata, 2011). In the source region of the mainshock, several large earthquakes having a magnitude greater than 7 occurred,

\footnotetext{
*Present address: National Research Institute for Earth Science and Disaster Prevention, Tsukuba 305-0006, Japan.

Copyright (C) The Society of Geomagnetism and Earth, Planetary and Space Sciences (SGEPSS); The Seismological Society of Japan; The Volcanological Society of Japan; The Geodetic Society of Japan; The Japanese Society for Planetary Sciences; TERRAPUB
}

doi:10.5047/eps.2012.09.003 and the source regions of these earthquakes were obtained (Yamanaka and Kikuchi, 2004). However, the magnitude of the 2011 earthquake was larger than those of previous large earthquakes and the source region of the mainshock seems to contain those of the previous earthquakes.

Relating to the large magnitude of the mainshock, a large slip, greater than $20 \mathrm{~m}$, is estimated near the hypocenter from various geophysical data (e.g. Ozawa et al., 2011; Yagi and Fukahata, 2011). A large tsunami, excited by the mainshock, damaged a wide coastal area of northwestern Japan, and was observed by ocean-bottom pressure meters, GPS wave gauges and many coastal tide gauges. From the tsunami data, a large slip (approximately $50 \mathrm{~m}$ ) on the plate boundary near the Japan Trench was estimated (Fujii et al., 2011; Maeda et al., 2011). The technique of sea floor geodetic observations using a GPS/acoustic combination enables us to measure sea-floor movement directly, and the movement of the sea floor during the mainshock reached $24 \mathrm{~m}$ in the off-Miyagi region (Sato et al., 2011). After the occurrence of the mainshock, many aftershocks occurred. From the epicentral distribution of the aftershocks as measured by a land-based seismic network, the source region of the earthquake is also considered to spread over a large re- 
gion $500 \mathrm{~km}$ wide. Several aftershocks have magnitudes greater than seven. The largest aftershock of magnitude $(M=7.7)$ occurred thirty minutes after the mainshock in the southernmost area of the source region. Obtaining a precise aftershock distribution is essential for understanding the generation mechanism of such a large earthquake. In addition, this kind of information provides useful constraints for studies of rupture over such a wide source region. The precise determination of aftershock distribution is difficult using only land seismic network data in the case that the source region is situated under an offshore area far from a coast line. It is widely known that an ocean-bottom seismometer (OBS) observation is useful for obtaining a high-resolution aftershock distribution of large earthquakes which have occurred under the sea floor (e.g., Shinohara $e t$ al., 2004; Sakai et al., 2005; Araki et al., 2006; Hino et al., 2006; Shinohara et al., 2008).

Magnitude 7 class earthquakes have repeatedly occurred beneath the landward slope of the Kuril and Japan Trenches considering the time intervals of large earthquakes, the probability of occurrence of an earthquake with a magnitude of 7.5 in the next 30 years is estimated to be $99 \%$ off Miyagi region. Based on this high probability, continuous OBS observation is being performed in the region off Miyagi. In addition, repeating large characteristic earthquakes with a magnitude of 7 have occurred at intervals of approximately 20 years in the off-Ibaraki region (Mochizuki et al., 2008). To investigate the mechanism of the repeating earthquakes, thirty-four long-term OBSs were deployed in the off-Ibaraki region following the occurrence of the 2011 earthquake. In 1997, a cabled ocean-bottom tsunami and seismic observation system was deployed in the region off Sanriku for real-time observations. This system has three seismometers, and two tsunami-meters and observed the mainshock. These data from the OBSs observing the mainshock and aftershocks should play an important role in the improvement of hypocenter location in the source region. However, the number of deployed OBSs is insufficient to obtain the precise hypocenter distribution in the whole source region of the 2011 Earthquake. To reveal the precise aftershock distribution, an OBS network covering the whole source region is needed.

Four days after the mainshock, we started an aftershock observation using pop-up-type OBSs in order to obtain the detailed aftershock activity of the 2011 Tohoku Earthquake (Shinohara et al., 2011). We repeated the deployment and recovery of the OBS four times. This paper focuses on the precise aftershock distribution in the whole source area, with an emphasis on the depths of events, using the OBS data from the first- and second-period observations, and we discuss the aftershock activity during the first three months after the mainshock.

\section{Observation}

The aftershock observations, using a huge number of OBSs, was initiated just after the 2011 off the Pacific coast of Tohoku Earthquake. Because the total observation has already been reported in detail (Shinohara et al., 2011), here we briefly describe the part of the OBS observations which produced the data for this paper. Four days after the 2011 off the Pacific coast of Tohoku Earthquake, we started to deploy seventy-two OBSs in the source region by R/V Kairei, belonging to the Japan Agency for Marine-Earth Science and Technology (JAMSTEC), and M/V Shinyu-maru, belonging to Shin Nippon Kaiji Co., chartered by the Earthquake Research Institute, University of Tokyo, in order to study the aftershock activity of this event. Consequently, we started observations of the aftershocks at a total of 121 sites, including the pre-installed OBS sites, from the end of March, 2011 (The first-period observation) (Fig. 1). The observation area was $500 \mathrm{~km} \times 200 \mathrm{~km}$ and had a high aftershock activity, which was estimated from the land seismic network. The spatial interval of the OBSs was approximately $25 \mathrm{~km}$ to cover the whole source region. The deployed OBSs in the northern and southern source areas in March, 2011, were recovered by using R/V Ryofu-maru and R/V Keifu-maru (both belonging to JMA) in April and early May. Sixty-five OBSs for the first-period observation were finally recovered. We deployed OBSs at the same site where the OBS for the first-period observation had been deployed by using R/V Kairei and R/V Ryofu-maru, and OBSs were deployed at an additional site to enlarge the observation area (Fig. 1) (second-period observation). In total, sixty-five OBS were deployed for the second-observation period. Seventy-seven OBSs were recovered by using R/V Natsushima, R/V Yokosuka (both belonging to JAMSTEC) and R/V Keifu-maru. For the first- and second-period observations, we deployed, in total, 137 OBSs for the aftershock observations.

We use various types of digital recording OBS systems. Most of the OBSs have three-component velocity sensitive electro-magnetic geophones with a natural frequency of $4.5 \mathrm{~Hz}$, and employ a glass sphere as a pressure vessel. The maximum recording period is approximately three months. We also use long-term OBSs, which have $1-\mathrm{Hz}$ 3-component geophones and a titanium pressure capsule. The longest recording period is 1 year for this type of OBS (Kanazawa et al., 2009). Broadband-type OBSs (BBOBSs), which have broadband seismometers with a large dynamic range, were also deployed. An observational band for the BBOBS is $360 \mathrm{~s}-100 \mathrm{~Hz}$ and the BBOBS have a precise absolute pressure gauge for the detection of long-period events and vertical crustal movement. The resolution of the $\mathrm{A} / \mathrm{D}$ conversion is 24 bits. Accurate timing, estimated to be within $0.05 \mathrm{~s}$, is provided by a precise crystal oscillator. All the OBSs are of a pop-up type with an acoustic release system. The OBS position at the sea floor was estimated by using acoustic ranging and ship GPS positions. The accuracy of the OBS positions at the sea floor is estimated to be a few tens of meters. We also determined the water depth of the OBSs by acoustic ranging.

\section{Data and Hypocenter Determination}

We used waveform data from the OBSs for 1st- and 2ndperiod observations just after the mainshock to mid-June, 2011. Approximately three months data were processed for a location of aftershocks. Because the OBS network covered widely the whole source region, heterogeneity of seismic velocity should largely affect the hypocenter determination of aftershocks. To minimize any influence of the 
(a)

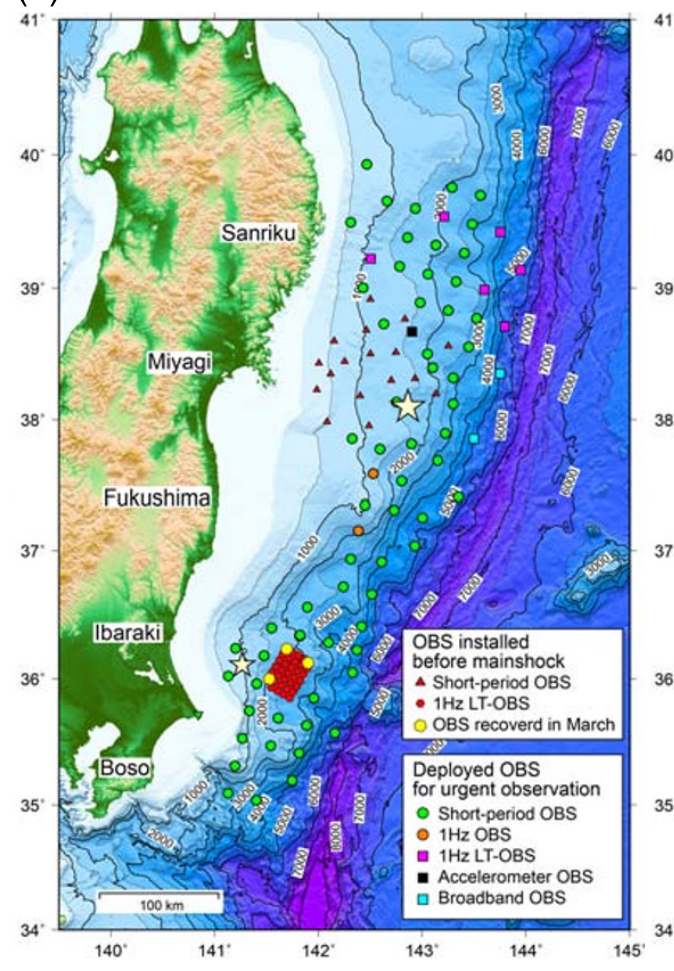

(b)

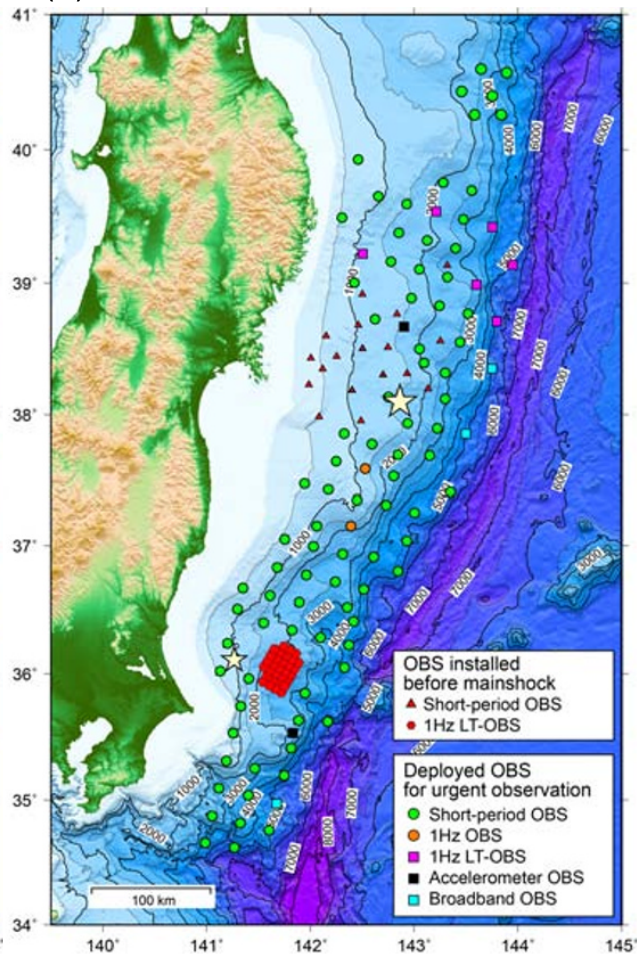

Fig. 1. Location map of ocean bottom seismometers with bathymetric features. Triangle and hexagons indicate the positions of pop-up-type OBSs which were deployed before the mainshock. Circles and squares denote the positions of OBSs which were deployed for an urgent observation after the mainshock. Various type of OBSs were used for aftershock observations. See inset legend. Yellow hexagons indicate the position of the OBSs which were recovered on March 30th. Large and small stars indicate the epicenters of the mainshock and the largest aftershock, respectively. (a) For the first-period observation from March 14 to the end of April, 2011. (b) For the second-period observation from the end of April to the middle of June.

heterogeneity of seismic velocity in the study area, we divided the observation area into three regions and the locations of aftershocks was carried out for each region. The results from each region were combined to obtain the aftershock distribution of the whole region. The border zones of the three regions overlap. For a combination of the results from the three areas, we selected earthquakes with a small error of location for each area and individual results were merged. Although there is a possibility that some gap in the hypocenter location exists in the border zones, this error is estimated to be smaller than a few kilometers because of the high resolution of the locations and the similarity of the velocity structures for the three regions.

The JMA had determined event positions using data of the permanent telemetered land seismic network, operated by the National Research Institute for Earth Science and Disaster Prevention (NIED), JMA, and universities (the JMA unified hypocenter catalog). We selected 1908 events whose epicenter is located below the OBS network. Data from all OBSs in each region were combined into multistation waveform data files for each event. $P$ - and $S$ wave arrival times were determined from a computer display (Urabe and Tsukada, 1991).

Using a precise velocity structure in the study region is important for an accurate hypocenter location. There are many seismic velocity surveys using OBSs in the study regions. Although the study area may have a large lateral heterogeneity in the seismic structure caused by the plate

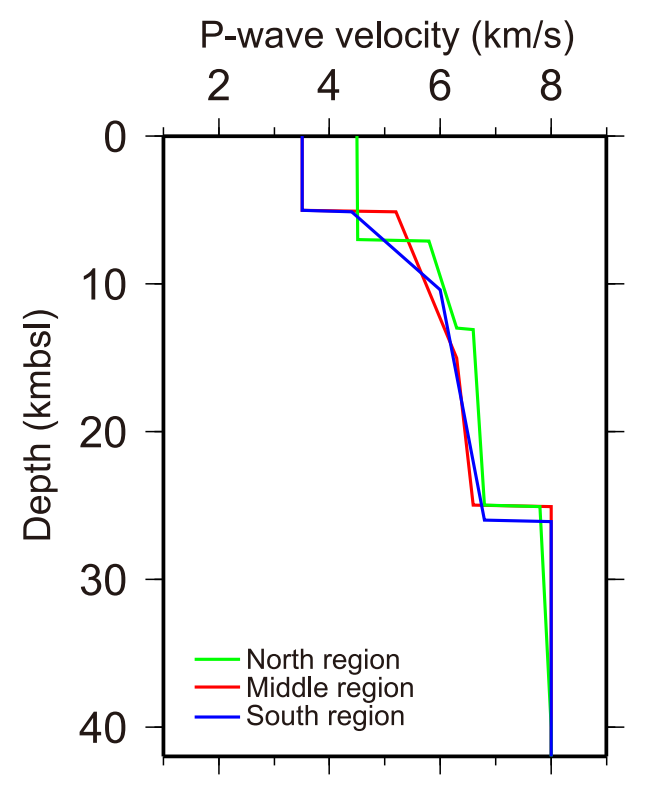

Fig. 2. $\quad P$-wave velocity structure models for the hypocenter locations. The observation area was divided into three regions and the location of aftershocks was carried out in each region individually. The models were derived from the refraction experiment carried out using OBSs in the each region (Takahashi et al., 2004 for the northern area; Miura et al., 2003 for the middle area; and Nakahigashi et al., 2012 for the southern area.) 
subduction, a simple one-dimensional velocity structure for the hypocenter location was modeled by introducing the results of a refraction study whose profile was laid in each study area. The velocity structures for the hypocenter location were derived from the results of Takahashi et al. (2004) for the northern region, Miura et al. (2003) for the middle region, and Nakahigashi et al. (2012) for the southern region. The profiles were selected to be situated in the regions for hypocenter location. Therefore, we extracted a one-dimensional velocity structure in the center of the region from the results of the refraction surveys to minimize the effect of heterogeneity.

Differences among the velocity structures for the three regions are not large. The first layers have a $P$-wave velocity of $3.5 \mathrm{~km} / \mathrm{s}$ for the middle and southern regions. In the northern region, the $P$-wave velocity is $4.5 \mathrm{~km} / \mathrm{s}$ for the first layer. The $P$-wave velocities for the first layer seem to be larger than the actual $P$-wave velocities of the sedimentary layer. Differences are compensated for by using $P$-wave station corrections for each station. The second layers have $P$-wave velocities from $4.5 \mathrm{~km} / \mathrm{s}$ to $6.2 \mathrm{~km} / \mathrm{s}$ and a large velocity gradient. Thicknesses of the second layers are approximately $8 \mathrm{~km}$ for the three models. Third layers have a $P$-wave velocity of approximately $6.5 \mathrm{~km} / \mathrm{s}$ with a small vertical velocity gradient and are $12 \mathrm{~km}$ thick. Fourth layers have $P$-wave velocity of $8 \mathrm{~km} / \mathrm{s}$ and the depth of the top of the fourth layer is approximately $25 \mathrm{~km}$ below sea level (Fig. 2). We also assumed that the ratio of $P$-wave to $S$-wave velocities in all layers is 1.73 , because the $S$-wave structure is not estimated in the seismic surveys. Since the thickness of sedimentary layers changes at each OBS site, the estimated travel times by the location program must be corrected. First, we measured the time differences between the $P$-wave arrival and the $P S$ converted wave arrival, or $S P$ converted wave arrival and $S$-wave arrival. Using these time differences, we calculated the initial station correction on the assumption of the $P$-wave velocity in the sedimentary layer. Hypocenters were determined by a maximum-likelihood estimation technique of Hirata and Matsu'ura (1987). Due to the uncertainty in the thickness and velocity of the sedimentary layer, we used the following method. First, we located the hypocenter using $P$ - and $S$-wave arrival times with initial correction values for the sedimentary layer. Averaged differences between observed travel times and estimated travel times (O-C times) were calculated for each OBS. Next, we located the hypocenter using the averaged $\mathrm{O}-\mathrm{C}$ times as correction values. A new set of averaged $\mathrm{O}-\mathrm{C}$ times for each OBS were calculated from the results of the second locations. Finally, the new averaged $\mathrm{O}-\mathrm{C}$ times were added to the previous correction values, and the hypocenters were again relocated. We repeated the relocation process using the last procedure until the root-mean-square of $\mathrm{O}-\mathrm{C}$ times become sufficiently small. It is commonly known that a ratio of $P$-wave velocity and $S$-wave velocity $\left(V_{p} / V_{s}\right.$ ratio) in sedimentary layer is greater than 1.73. Therefore, we estimate a set of station correction values for the $S$-wave with several differences by assuming the $V_{p} / V_{s}$ ratio in the sedimentary layer. At last, we chose a set of station corrections which gave the smallest O-C times. Magnitudes of the aftershocks were adopted from the JMA unified hypocenter catalog which the JMA determined by using a land-based seismic network. Finally, we estimated focal mechanisms of aftershocks using the polarities of the first $P$-wave arrivals recorded by the OBSs using the computer program described in Reasenberg and Oppenheimer (1985). For the estimation of focal mechanisms, we used at least $6 P$-wave polarity data. In consideration of the small number of polarity data from the OBSs, earthquakes which did not have a unique focal solution were not considered.

\section{Results and Discussion}

In total, 1908 events which were selected from the JMA catalog were able to be located. We selected the events with more than three $P$-wave arrival readings and more than one $S$-wave reading from the OBS networks. The OBS networks located 906 earthquakes with an error of less than $5 \mathrm{~km}$ in the horizontal direction and less than $3 \mathrm{~km}$ in depth. The estimation errors of each aftershock location were calculated from the total covarience matrix of the location program (Hirata and Matsu'uura, 1987). The magnitudes of these 906 aftershocks range from 1.9 to 5.7. The epicenters of these aftershocks are limited to be within, or near, the OBS networks used in this study. In other words, the resolution of hypocenters is significantly high within the OBS network. In addition, we add the events which were also located by the OBS network by Shinohara et al. (2011). In total, 1005 events with a spatially high resolution were obtained (Fig. 3). The obtained aftershock distribution is not uniform in time and space; however, the positions of the located aftershocks by the OBS data have a high resolution. Because we selected the events from the JMA unified hypocenter catalog, we can compare hypocenters which are located by the OBS data with those determined from the data of the land seismic network by the JMA (Fig. 4). Differences in the epicenters are relatively small; however, the depths of events have large differences. Hypocenters determined by the JMA in the study area are scattered over a large depth range of approximately $80 \mathrm{~km}$, especially near the trench region. Hypocenters determined by the OBS network are more concentrated in depths of less than $60 \mathrm{~km}$. This indicates that OBS observations are useful for the determination of the depth of each event with a higher accuracy. In general, aftershocks were re-located shallower in comparison with those determined using land station data only. This tendency is clearly recognized in the middle and southern regions.

The epicenter distribution is not uniform. In the epicenter distribution, the aftershocks may be divided into a number of clusters from a geometrical viewpoint. Most of the aftershocks have a depth shallower than $60 \mathrm{~km}$. The aftershocks form a plane dipping landward over the whole area, which is consistent with the result that the mainshock is an interplate earthquake. Aftershocks beneath the slope on the island arc side are frequent, and there is relatively low seismic activity beneath the area within the trench region where the water depth is greater than about $3000 \mathrm{~m}$. The landward slope close to the Japan Trench off Miyagi is estimated to be a source region of the large tsunami during the mainshock (Fujii et al., 2011; Maeda et al., 2011) Aftershocks 

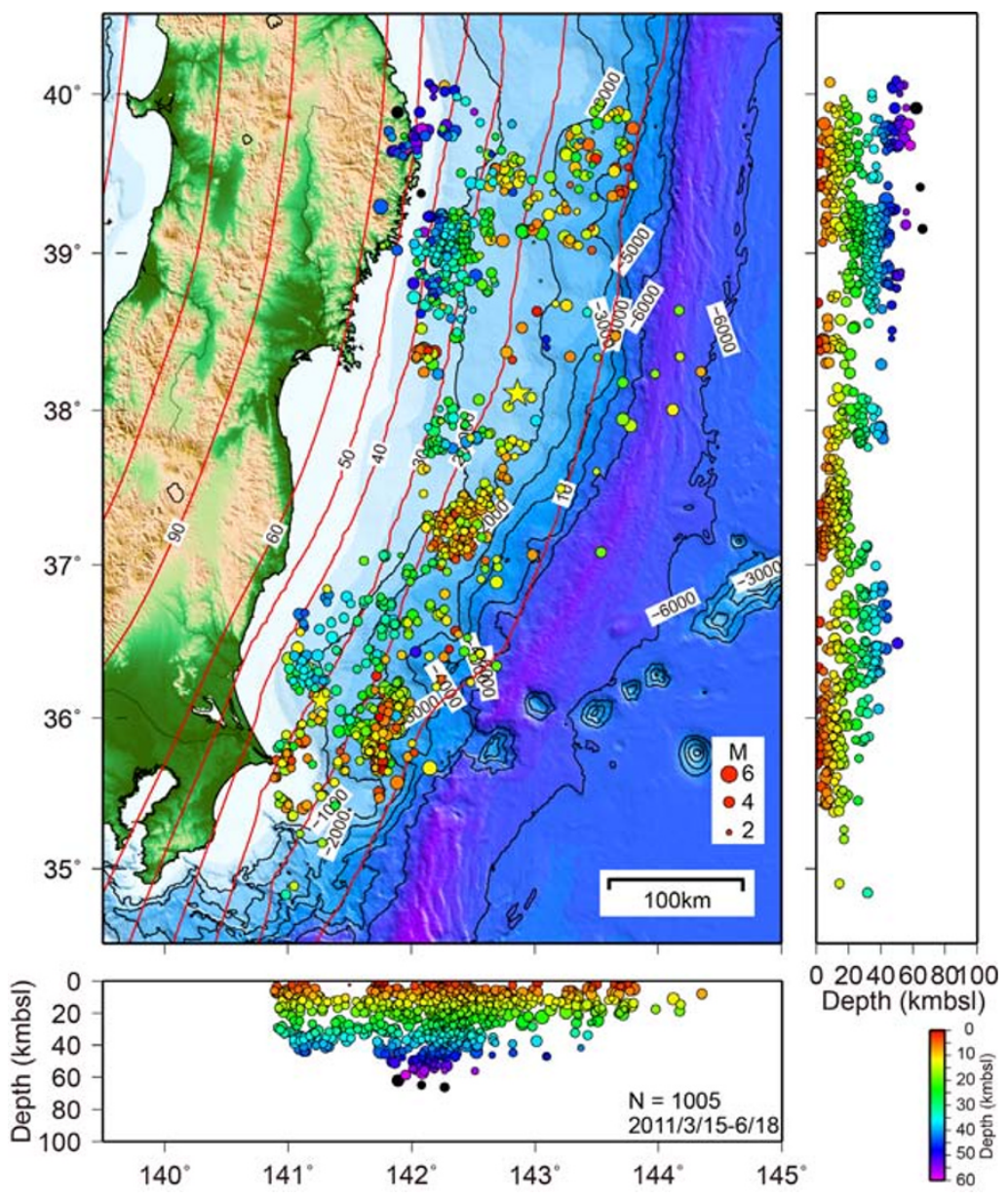

Fig. 3. Final hypocenter distribution (March 15th-June 18th, 2011) derived by using the maximum-likelihood estimation technique with bathymetry. The circles filled with color indicate the hypocenters of aftershocks located with a spatially high resolution. The depth of events are color-coded, and diameters of the circles are proportional to magnitudes. Red contours indicate depths of surface of the subducting Pacific plate by a model estimated from hypocenter distribution and seismic structures using OBSs. No exaggeration for the vertical direction is applied. In the epicenter distribution, the aftershocks may be divided into a number of clusters from a geometrical viewpoint. In the vertical section, the concentration of the aftershocks in depths shallower than $60 \mathrm{~km}$ is clearly recognized. From the W-E vertical cross-section, the aftershocks become deeper to the westward.

were located near this tsunami source region in contrast to low seismicity in other trench regions. In the off-Miyagi region, aftershocks with depths around $30 \mathrm{~km}$ also occur in the center of the Japan Trench.

Seismicity in the plate boundary region off Tohoku before the mainshock was obtained by several researches using land-based data (e.g. Hasegawa et al., 1994; Umino et al., 1995; Gamage et al., 2009), and the position of the plate boundary below the landward slope was estimated and a double-planed seismic zone was found. As a result of marine seismic observations using OBSs (e.g. Hino et al., 1996, 2006; Koga et al., 2012; Suzuki et al., 2012), precise seismic activities were estimated. From 2004 to 2008, dense seafloor earthquake observations, using longterm OBSs, were made in the landward slopes of the Kuril and Japan Trenches to obtain a precise hypocenter distribution (Shinohara et al., 2009; Yamada et al., 2011). In addition, aftershock observations of the 2003 Tokachi-oki earthquake, which was a large interplate earthquake, were carried out (Shinohara et al., 2004; Yamada et al., 2005). From these sea-floor observations, a precise hypocenter distribution before the 2011 earthquake was obtained. From the results of seismic marine surveys and this high-resolution hypocenter distribution, a detailed geometry of the subducting Pacific plate was estimated (Shinohara et al., 2009). The dip angle of the subducting Pacific plate is small in the northern Japan Trench region, and the dip angle increases rapidly at depths of about $25 \mathrm{~km}$. A slip distribution of the mainshock has been estimated by many studies. These researches were based on geodetic data (e.g. Miyazaki et al., 2011; Pollitz et al., 2011; Evance and Meade, 2012) or tsunami data (e.g. Saito et al., 2011; Yamazaki et al., 2011). A slip distribution was also estimated by a joint inversion technique of GPS, teleseismic, and tsunami, data (e.g. Simons et al., 2011; Yokota et al., 2011). Yoshida et al. (2011) derived a slip distribution during the 2011 mainshock from teleseismic $P$-waves and regional strong motion data, and the results of Yoshida et al. (2011) are considered to be suitable for comparison with the aftershock distribution, because the slip distribution using strong motion data should correspond with the radiation of seismic waves. We can compare the aftershock distribution, from the OBS data, with these results of the previous study (Fig. 5).

In the northern region, which is the off-Sanriku and offMiyagi regions, the activity of the aftershocks is high beneath the landward slope. There is low seismicity in the 

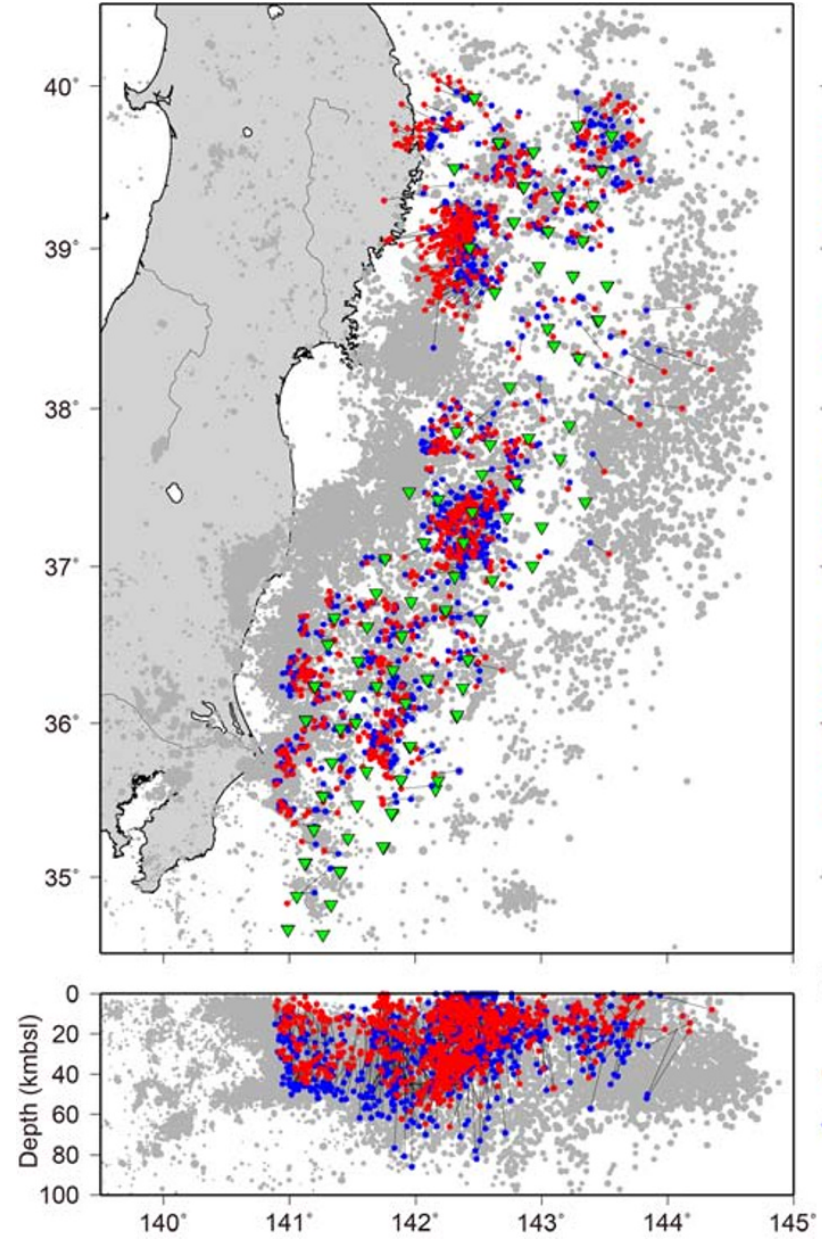

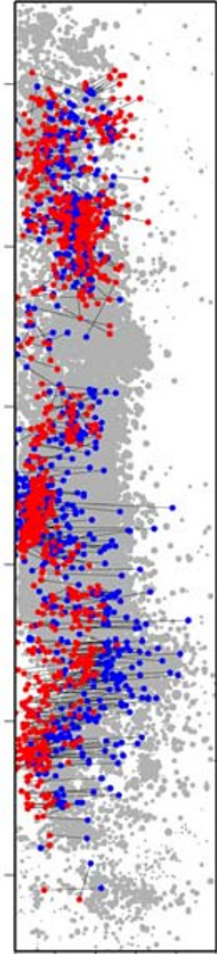

$0 \quad 204060 \quad 80100$ Depth (kmbsl)

- OBS network

- Land-based

network data only

Fig. 4. Comparison of hypocenters determined by the OBS networks (red circles) and those determined by the JMA (blue circles). The inverted green triangles indicate the positions of the pop-up-type OBSs used for the locations. Grey circles indicate the hypocenters of aftershocks determined by the JMA from March 15th to June 18th. Note that the aftershock distribution obtained by this study is not uniform in time and space; however, positions of the re-located aftershocks have a spatially high resolution.

region where a large slip during the mainshock is estimated (Yoshida et al., 2011), which is consistent with the result of Asano et al. (2011). Especially there was little seismicity at the plate boundary. The region where, after the mainshock, seismicity at the plate boundary became low had shown an ordinary seismic activity before the mainshock (Fig. 5). In the middle region, which is the offFukushima region, aftershocks mainly occurred along the plate boundary; however, there was also aftershock activity in the landward plate. The region with low seismicity is off Fukushima. Although this region had low seismicity before the mainshock, Yokota et al. (2011) reported, from using strong motion data, that large seismic energy was released from this area during the mainshock. In the southern region, which is the off-Ibaraki and off-Boso regions, there was a high seismic activity in the plate boundary region. In addition, aftershock activity was also high in the landward plate. A deep earthquake, whose depth was approximately $50 \mathrm{~km}$, occurred below the landward slope having a water depth of about $3000 \mathrm{~m}$ off Ibaraki. On the other hand, aftershock activity is low in the region near the Japan Trench. There also seems to have been a low seismicity in the source region of the $M 7.7$ aftershock, which occurred 30 minutes after the mainshock. In the southern region, the Philippine
Sea plate is considered to be subducting below the landward plate (e.g. Nakahigashi et al., 2012). Before the mainshock, several seismic gaps near the edge of the Philippine Sea plate were found (Yamada et al., 2011). In the aftershock distribution of the 2011 mainshock, we also see low seismic activities in the region where seismic gaps existed before the mainshock. It is inferred that the seismicity in this region is related to heterogeneity.

Because many seismic velocity surveys using OBSs have been carried out in the source region of the mainshock, the obtained hypocenter distribution can be compared with the results of previous seismic surveys. Although our location of the aftershocks was based on a one-dimensional velocity structure, systematic errors in hypocentral positions are estimated to be comparable to a few kilometers because the velocity structures for the location were derived from the results of these seismic surveys. In a cross-section of the hypocentral distribution projected on a vertical plane along the seismic surveys (Miura et al., 2003; Takahashi et al., 2004; Nakahigashi et al., 2012; Shinohara et al., in preparation), we can clearly see the relation between the aftershock distribution and the seismic velocity structure (Fig. 6). Aftershocks occurred in the plate boundary region in all the profiles. However, there is no aftershock 
(a)

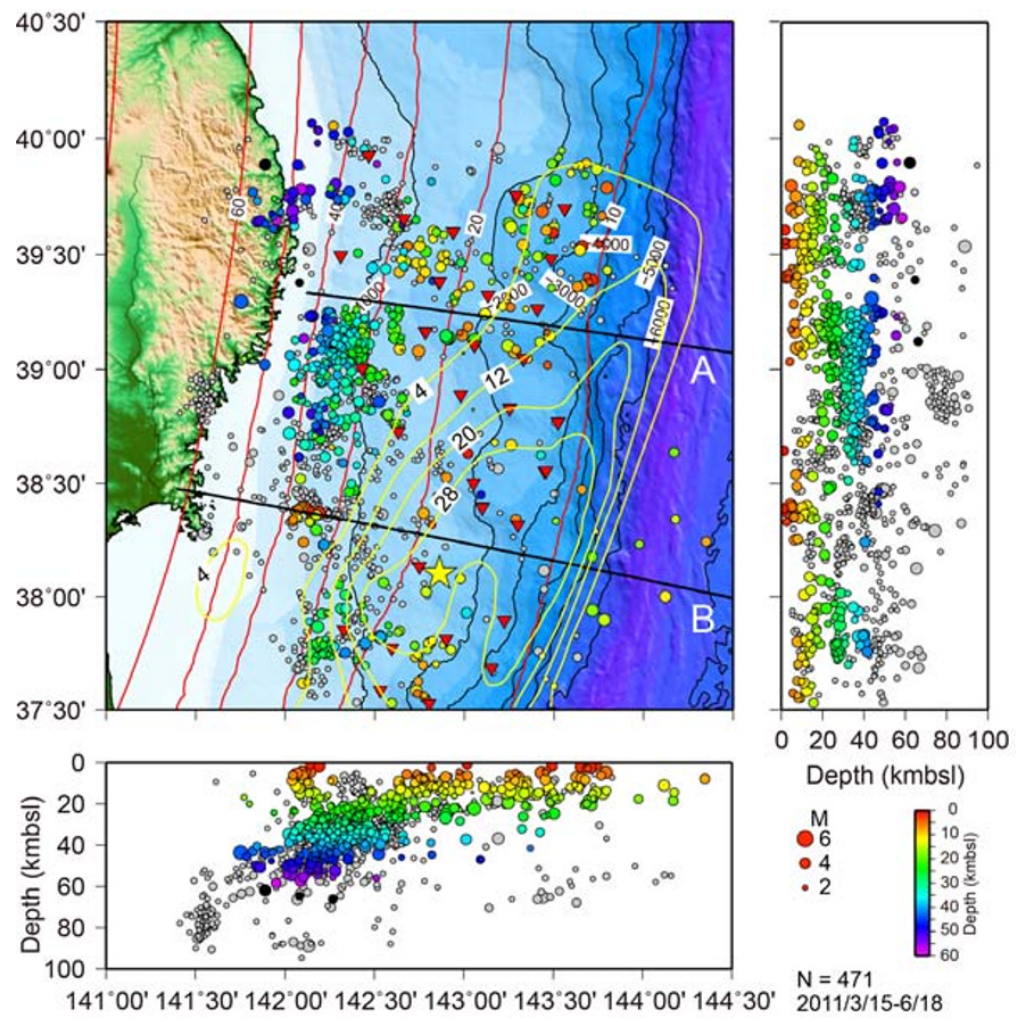

(b)
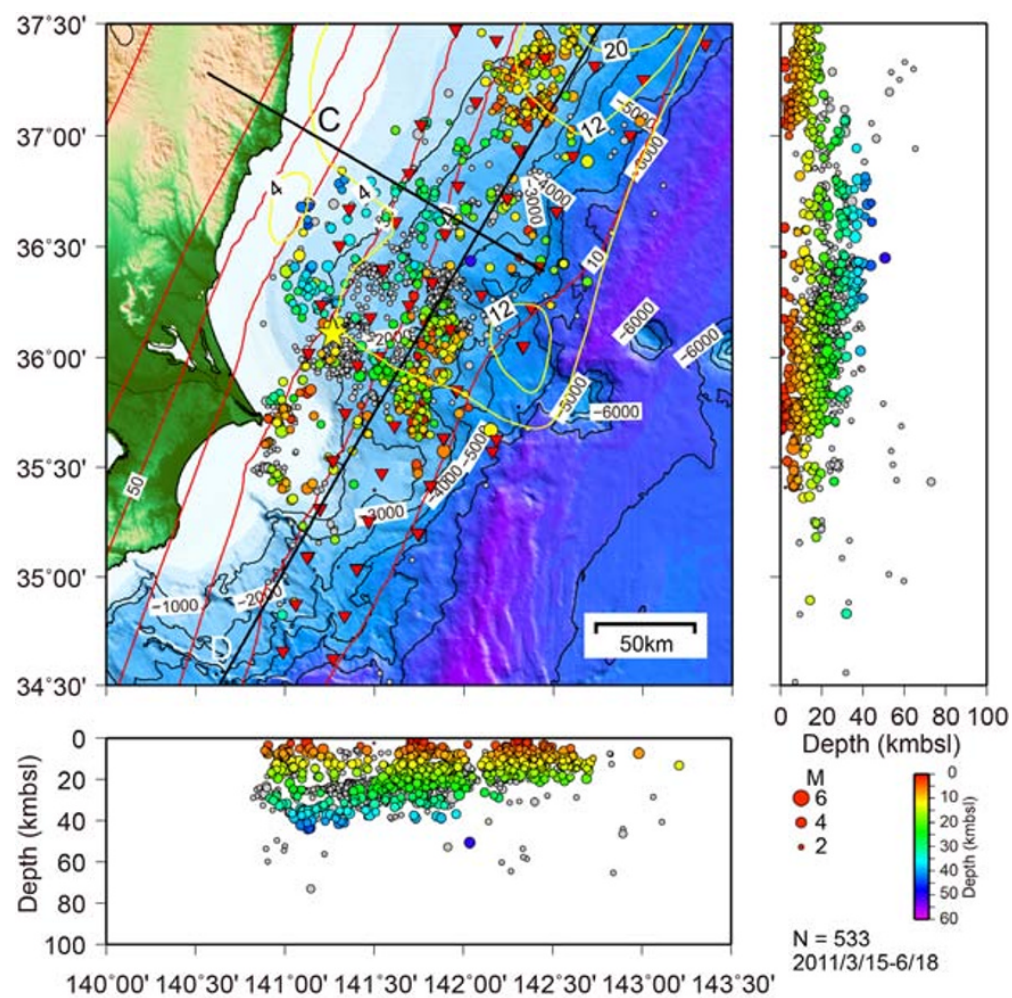

Fig. 5. Comparison of the final hypocenter distribution determined by the OBS networks to the hypocenter distribution before the mainshock and slip distribution during the mainshock using strong motion data (Yoshida et al., 2011). Long-term OBS data from 2004 to 2008 were used to obtain the hypocenter distribution before the mainshock. The inverted red triangles indicate the positions of the pop-up-type OBSs for the aftershock observation. The circles filled with color represent the hypocenters of aftershocks. Grey circles indicate the hypocenters of earthquakes before the mainshock. The thick line indicates the profile of the seismic survey. Red contours indicate depths of surface of the subducting Pacific plate by marine observations. (a) For the northern region. (b) For the southern region. (c) Comparison of the hypocenter distribution between the aftershocks and earthquakes before the mainshock by the OBS data for the northern region. Depth profiles along the east-west direction are shown. Red line indicates the position of the plate boundary. 
(c)
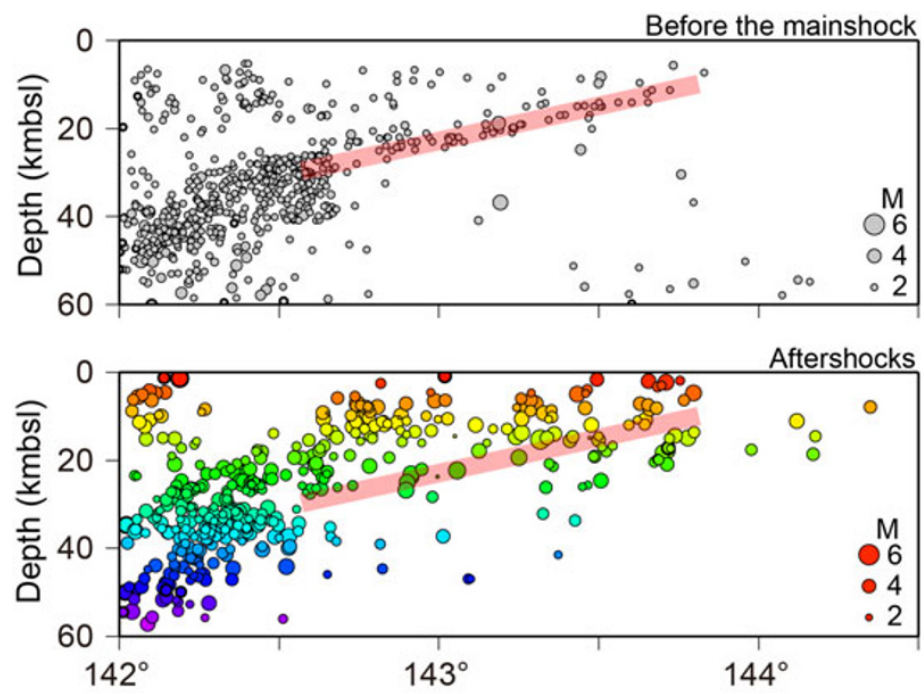

Fig. 5. (continued).

along the plate boundary at depths less than $25 \mathrm{~km}$ in the region off Miyagi (Fig. 6(b)). The plate boundary region with little seismicity off Miyagi corresponds to the region where a slip on the plate boundary during the mainshock is greater than $12 \mathrm{~m}$. Before the 2011 mainshock, small earthquakes mainly occurred along the plate boundary, even in this region (Shinohara et al., 2009). We infer that the stress field near the plate boundary in this region may change due to the mainshock. On the other hand, high seismic activities are estimated in the plate boundary region, where the depth is greater than $30 \mathrm{~km}$, for all the profiles. Activity of aftershocks within the landward plate is high for all the profiles, especially in the region off Sanriku, Ibaraki and Boso. In the land of the northeastern Japan arc, it is reported that shallow seismic activity in the crust increased significantly after the mainshock, and a static stress change which possibly triggered those post-mainshock earthquake sequences was suggested (e.g. Kato et al., 2011; Okada et al., 2011). This type of stress change may occur just above the source region of the mainshock. There are also aftershock activities within the Pacific plate in all regions, however the seismicity is not high. The seismic activity in a deep region of the subducting Pacific plate near the Japan Trench was also reported before the 2011 mainshock occurrence (Shinohara et al., 2005; Gamage et al., 2009; Mizuno et al., 2009; Koga et al., 2012). In the southernmost region, the aftershocks mainly occurred around the plate boundary between the landward plate and the subducting Pacific plate (Figs. 6(c) and (d)). In addition, hypocenters of the aftershocks are spread in the subducting oceanic crust and the crust in the landward plate. The aftershocks seem to be concentrated within the subducting oceanic crust and the $6.2-\mathrm{km} / \mathrm{s}$ layer in the overriding plate. The rupture of the mainshock is estimated to propagate from the hypocenter which is positioned off Miyagi to the southward (e.g. Honda et al., 2011; Suzuki et al., 2011; Yagi and Fukahata, 2011; Yoshida et al., 2011). The velocity structure model, obtained by the seismic survey, clearly shows that the Philippine Sea plate is subducting below the landward plate (Fig. 6(d)). There were few aftershocks in the contact region between the Philippine Sea plate and the Pacific plate. Therefore, it is interpreted that the propagation of the rupture during the mainshock sequence was terminated at the contact (Shinohara et al., 2011).

Focal mechanisms of the aftershocks are determined using data of polarities of first arrivals recorded by the OBSs using the program of Reasenberg and Oppenheimer (1985), and 121 focal mechanism solutions were obtained (Fig. 7). In addition, we selected 31 events which correspond to our results from the catalog of focal solutions determined by the automated moment tensor determination, using Japanese land seismic network data (F-net) (Fukuyama et al., 1998). Because the geometry of the subducting Pacific plate had been estimated from results of seismic marine surveys and long-term OBS observations, the aftershocks can be classified by their depths using the plate boundary geometry model. We classified aftershocks into three categories: events which occurred in the plate boundary region where the distance to the plate boundary is less than $5 \mathrm{~km}$; the landward plate region where depths are $5 \mathrm{~km}$ shallower than the plate boundary; and the oceanic plate region where depths are $5 \mathrm{~km}$ deeper than the plate boundary. For classification of the F-net focal mechanisms, the OBS results were used for the positions of events. In the plate boundary region, many events occur having a reverse fault (thrust) type mechanism. However, normal fault, and strike-slip, types are also observed. To take into account ambiguity in the position of the plate boundary, the plate boundary region is defined to have a thickness of $10 \mathrm{~km}$. Therefore earthquakes which did not occur just at the plate boundary should also be included. In other words, there is a possibility that normal fault, and strike-slip, type earthquakes occurred close by the plate boundary. In the landward plate and the oceanic plate regions, aftershocks of normal fault type or strike-slip type are dominant. Before the occurrence of the mainshock, most of the events in the plate bound- 
(a)

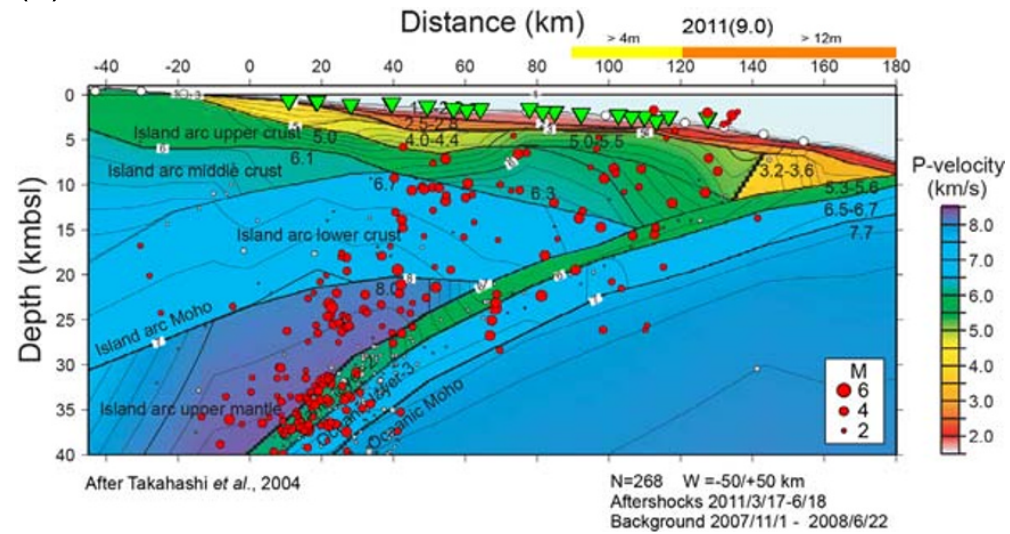

(b)

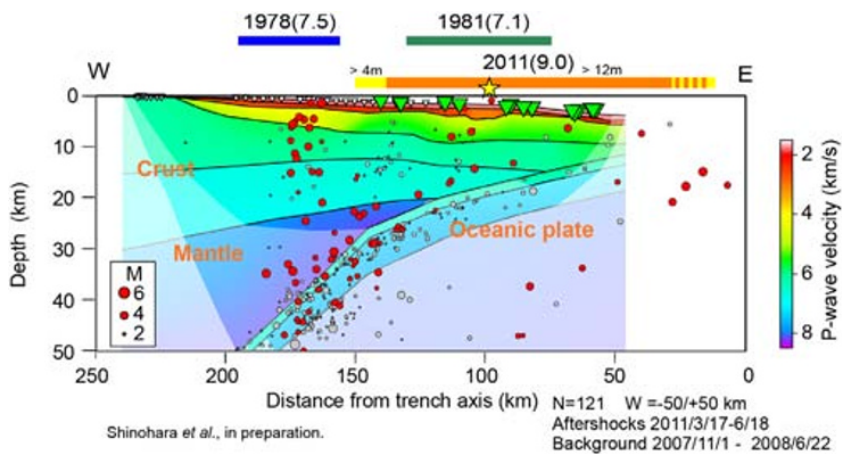

(c)

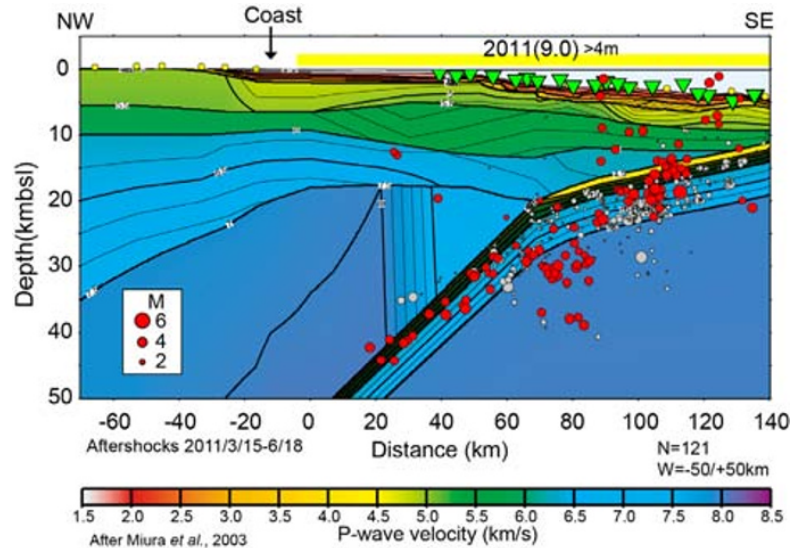

(d)

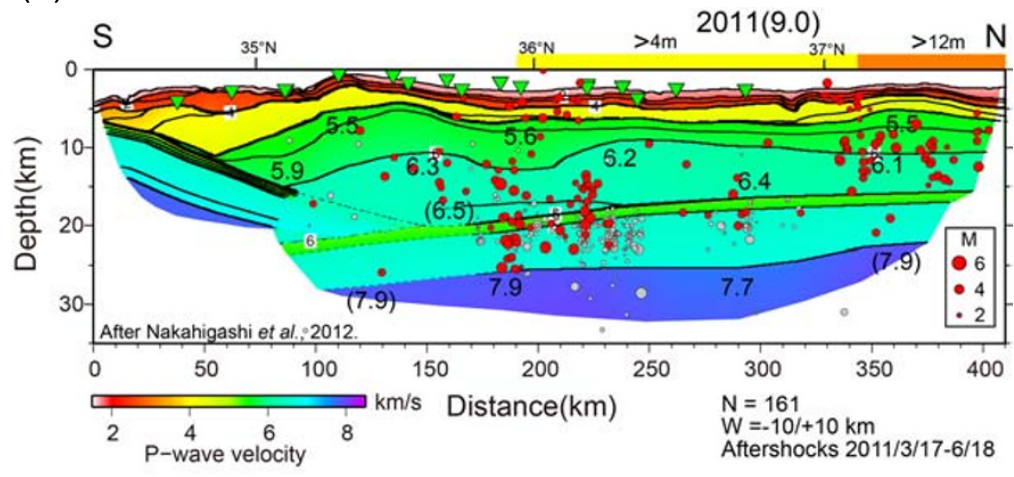

Fig. 6. Vertical sections of $P$-wave velocity structures and the aftershock distribution along the refraction profile (a) for the off-Sanriku region, (b) for the off-Miyagi region, (c) for the off-Fukushima region, and (d) for the off-Ibaragi region. Profiles (a), (b), (c) are perpendicular to the Japan Trench, and profile (d) is parallel to the trench. Positions of each profiles are indicated in Fig. 5. The aftershocks within a 50-km wide box on both sides along the profile are projected onto the seismic survey profiles for profile a), b), and c). For profile d), a box wide is $10 \mathrm{~km}$. Red circles indicate the hypocenters of the aftershocks, and diameters of circles correspond to magnitudes. Inverted triangles indicate the projected position of the OBSs for aftershock observations. Orange and yellow bars above the structure indicate the region where slip is greater than $12 \mathrm{~m}$ and $4 \mathrm{~m}$, respectively. Grey circles indicate hypocenters from the previous OBS observations before the mainshock. 

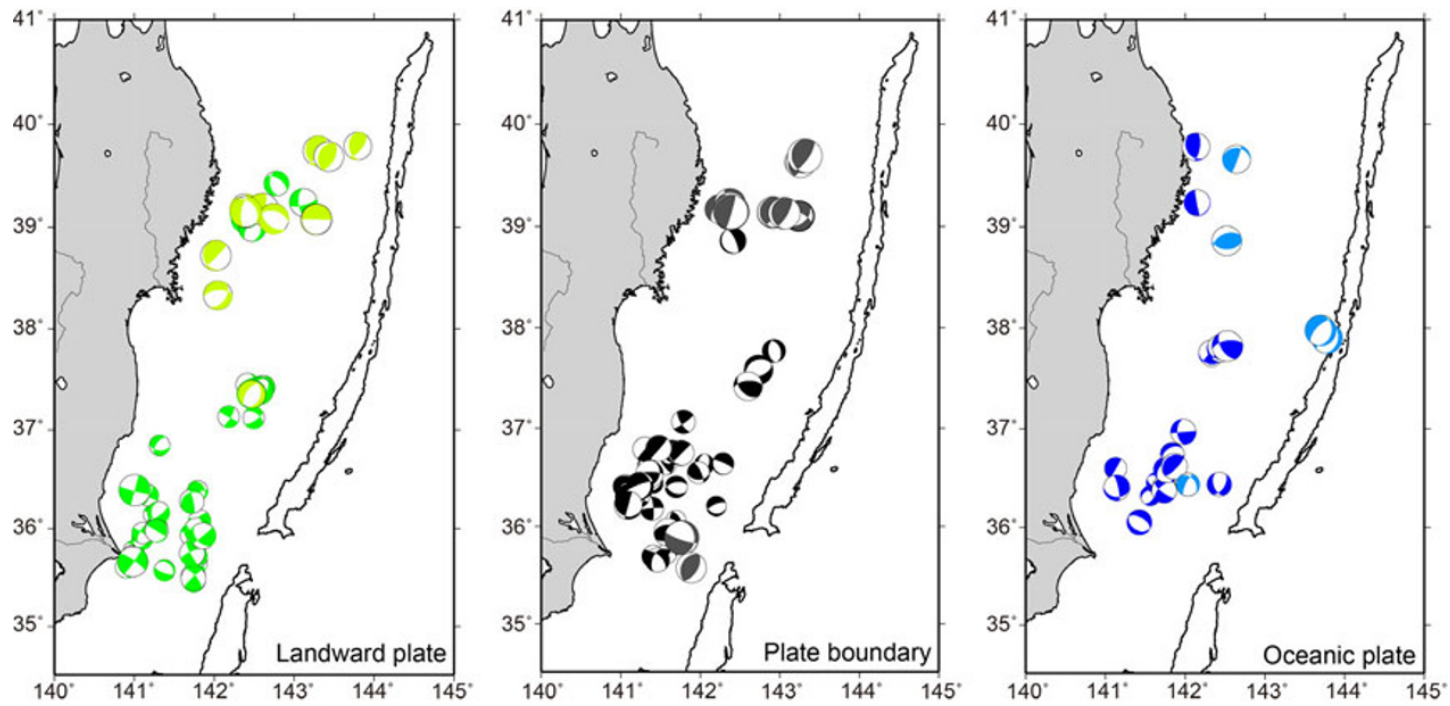

Fig. 7. Focal mechanisms of the aftershocks are determined using data of polarities of first arrivals recorded by the OBSs. The aftershocks are classified by their depths. The event classified into the plate boundary region has distances between its hypocenter and the plate boundary is less than $5 \mathrm{~km}$. In addition, focal mechanisms determined using F-net data are also plotted. For classification of F-net focal mechanisms, the OBS results were used for positions of the events. The F-net results are indicated by light color.

ary and the landward plate regions were reported to have a reverse fault (thrust) type mechanism (e.g. Hasegawa et al., 2011). After the mainshock, seismic activity became higher and normal fault type, or strike-slip type, events were dominant in the landward plate region. Occurrence of normal fault type, or strike-slip type, events in the landward plate have also been reported by Asano et al. (2011) using landbased data. A change of focal mechanisms in the landward plate is thought to correspond with a stress change caused by a large slip at the plate boundary (Hasegawa et al., 2011; Kato et al., 2011; Imanishi et al., 2012; Yoshida et al., 2012). Within the oceanic plate, most earthquakes had a normal fault type, or strike-slip type, mechanism. Earthquakes at depths around $40 \mathrm{~km}$ in the subducting oceanic plate near the Japan Trench are considered to correspond to the lower plane of the double seismic zone (Shinohara et al., 2005; Gamage et al., 2009; Mizuno et al., 2009; Koga et al., 2012). Koga et al. (2012) reported that earthquakes which occurred in the shallower part have a focal mechanism of normal fault, and earthquakes with a reverse fault type mechanism occurred in the deeper part below the landward slope of the Japan trench. This seismic activity is considered to explain the response of bending of the lithosphere. However, aftershocks of the 2011 Tohoku earthquake within the subducting oceanic plate had mostly normal fault type, or strike-slip type, mechanisms. Obana et al. (2012) found that earthquakes beneath the seaward slope of the Japan Trench after the mainshock occurred under a tensional stress field in all depths and concluded that the stress regime in the deep part of the subducting oceanic plate in the seaward slope had changed from compression to tension after the mainshock. Our results indicate that the tension stress field extends to the oceanic plate below the landward slope of the Japan Trench. The stress field of the subducting pacific plate in and around the source region of the 2011 mainshock is estimated to change as a result of the mainshock.

\section{Conclusions}

We carried out aftershock observations using pop-uptype OBSs in order to obtain a detailed aftershock distribution of the 2011 Tohoku earthquake. Deployment and recovery of the OBS were repeated four times, and we have used data from more than 70 OBSs recorded just after the mainshock to the middle of June, 2011. We selected 1908 events whose epicenters were located below the OBS network from the JMA earthquake catalog, and $P$ - and $S$-wave arrival times were picked from the OBS data. Hypocenters were estimated by a maximum-likelihood estimation technique and one-dimensional velocity structures were modeled using the results of previous refraction studies in the study region. Thickness changes of sedimentary layers at each OBS site were evaluated and estimated travel times by the location program were corrected. A precise aftershock distribution, for approximately three months over the whole source area, with an emphasis on the depths of events, using the OBS data, was obtained. The OBS networks located 1005 earthquakes with a high spatial resolution. The epicenter distribution is not uniform. In the epicenter distribution, the aftershocks may be divided into a number of clusters from a geometrical viewpoint. The aftershocks form a plane dipping landward over the whole area. Comparing our results with velocity structures from marine seismic surveys, there is no aftershock along the plate boundary in the region off Miyagi, where a large slip during the mainshock is estimated. A plate coupling in this region may change due to the occurrence of the mainshock. The activity of aftershocks within the landward plate above the source region is high, and many aftershocks within the landward plate had a normal fault type, or strike-slip type, mechanism. On the other hand, many events with a reverse fault (thrust) type mechanism occurred along the plate boundary. Within the subducting oceanic plate, most of earthquakes had a normal fault type, or strike-slip type, mechanism. The stress field in and around the source region of the 2011 mainshock 
changes as a result of the mainshock.

Acknowledgments. The work of the officers and crew of R/V Kairei, R/V Yokosuka, R/V Natsushima, R/V Ryofu-maru, R/V Keifu-maru, and M/V Shinyu-maru is appreciated. We express thanks to Ms. M. Oowada, Messrs. S. Hashimoto, T. Yagi, H. Abe, and K. Uchida for help in the preparation of the OBS observations. The support of Drs. K. Katsumata, R. Azuma, T. Isse, Y. Kaiho, H. Miyamachi, Y. Kaneda, and Mr. T. No for the observations, data processing and discussion have been essential for performing this study. We thank Ms. Y. Nihei for the OBS data processing. Drs. T. Kanazawa, N. Hirata, K. Obara, and S. Sakai gave us useful advice to carry out this study. We are also grateful to two anonymous reviewers and Dr. A. Hasegawa for their critical reviews for an improvement of the discussions. This study is partly supported by the Special Coordination Funds for the Promotion of Science and Technology (MEXT, Japan) titled as the integrated research for the 2011 off the Pacific coast of Tohoku Earthquake. Most of the figures were created using GMT (Wessel and Smith, 1991).

\section{References}

Araki, E., M. Shinohara, K. Obana, T. Yamada, Y. Kaneda, T. Kanazawa, and K. Suyehiro, Aftershock distribution of the 26 December 2004 Sumatra-Andaman earthquake from ocean bottom seismographic observation, Earth Planets Space, 58, 113-119, 2006.

Asano, Y., T. Saito, Y. Ito, K. Shiomi, H. Hirose, T. Matsumoto, S. Aoi, S. Hori, and S. Sekiguchi, Spatial distribution and focal mechanisms of aftershocks of the 2011 off the Pacific coast of Tohoku Earthquake, Earth Planets Space, 63, 669-673, 2011.

Evance, E. L. and B. J. Meade, Geodetic imaging of coseismic slip and postseismic afterslip: Sparsity promoting methods applied to the great Tohoku earthquake, Geophys. Res. Lett., 39, L11314, doi:10.1029/2012GL051990, 2012.

Fujii, Y., K. Satake, S. Sakai, M. Shinohara, and T. Kanazawa, Tsunami source of the 2011 off the Pacific coast of Tohoku Earthquake, Earth Planets Space, 63, 815-820, 2011.

Fukuyama, E., M. Ishida, D. S. Dreger, and H. Kawai, Automated seismic moment tensor determination by using on-line broadband seismic waveforms, Zisin, 51, 149-156, 1998 (in Japanese with English abstract).

Gamage, S. S. N., N. Umino, A. Hasegawa, and S. H. Kirby, Offshore double-planed shallow seismic zone in the NE Japan forearc region revealed by $\mathrm{sP}$ depth recorded by regional networks, Geophys. J. Int., 78, 195-214, 2009

Hasegawa, A., S. Horiuchi, and N. Umino, Seismic structure of the northeastern Japan convergent margin: A synthesis, J. Geophys. Res., 99, 22295-22311, 1994.

Hasegawa, A., K. Yoshida, and T. Okada, Nearly complete stress drop in the $2011 M_{\mathrm{w}} 9.0$ off the Pacific coast of Tohoku Earthquake, Earth Planets Space, 63, 703-707, 2011.

Hino, R., T. Kanazawa, and A. Hasegawa, Interplate seismic activity near the northern Japan Trench deduced from ocean bottom and land-based seismic observations, Phys. Earth Planet. Inter., 93, 37-52, 1996.

Hino, R., Y. Yamamoto, A. Kuwano, M. Nishino, T. Kanazawa, T. Yamada, K. Nakahigashi, K. Mochizuki, M. Shinohara, K. Minato, G. Aoki, N. Okawara, M. Tanaka, M. Abe, E. Araki, S. Kodaira, G. Fujie, and Y. Kaneda, Hypocenter distribution of the main- and aftershocks of the 2005 Off Miyagi Prefecture Earthquake located by ocean bottom seismographic data, Earth Planets Space, 58, 1543-1548, 2006.

Hirata, N., and M. Matsu'ura, Maximum-likelihood estimation of hypocenter with origin time eliminated using nonlinear inversion technique, Phys. Earth Planet. Inter., 47, 50-61, 1987.

Honda, R., Y. Yukutake, H. Ito, M. Harada, T. Aketagawa, A. Yoshida, S. Sakai, S. Nakagawa, N. Hirata, K. Obara, and H. Kimura, A complex rupture image of the 2011 off the Pacific coast of Tohoku Earthquake revealed by the MeSO-net, Earth Planets Space, 63, 583-588, 2011.

Imanishi, K., R. Ando, and Y. Kuwahara, Unusual shallow normal-faulting earthquake sequence in compressional northeast Japan activated after the 2011 off the Pacific coast of Tohoku earthquake, Geophys. Res. Lett., 39, L09306, doi:10.1029/2012GL051491, 2012.

Kanazawa, T., M. Shinohara, and H. Shiobara, Recent progress in seafloor earthquake observations and instruments in Japan, Zisin 2, 61, S55-S68, 2009 (in Japanese with English abstract).

Kato, A., S. Sakai, and K. Obara, A normal-faulting seismic sequence triggered by the 2011 off the Pacific coast of Tohoku Earthquake: Whole- sale stress regime changes in the upper plate, Earth Planets Space, 63, 745-748, 2011.

Koga, S., Y. Ito, R. Hino, M. Shinohara, and N. Umino, Focal mechanisms of small earthquakes within the Pacific plate near the Japan Trench, Zisin 2, 64, 75-90, 2012 (in Japanese with English abstract).

Maeda, T., T. Furumura, S. Sakai, and M. Shinohara, Significant tsunami observed at the ocean-bottom pressure gauges at 2011 off the Pacific coast of Tohoku Earthquake, Earth Planets Space, 63, 803-808, 2011.

Miura, S., S. Kodaira, A. Nakanishi, T. Tsuru, N. Takahashi, N. Hirata, and Y. Kaneda, Structural characteristics controlling the seismicity of southern Japan Trench fore-arc region, revealed by ocean bottom seismographic data, Tectonophysics, 363, 79-102, 2003.

Miyazaki, S., J. J. McGuire, and P. Segall, Seismic and aseismic fault slip before and during the 2011 off the Pacific coast of Tohoku Earthquake, Earth Planet Space, 63, 637-642, 2011.

Mizuno, M., T. Sato, M. Shinohara, K. Mochizuki, T. Yamada, and T. Kanazawa, Seismicity in the seaward slope of the Japan Trench, off Ibaraki, using ocean bottom seismometers for long-term observation, Zisin 2, 61, 19-23, 2009 (in Japanese with English abstract).

Mochizuki, K., T. Yamada, M, Shinohara, Y. Yamanaka, and T. Kanazawa, Weak Interplate Coupling by Seamounts and Repeating M 7 Earthquakes, Science, 321(5839), 1194-1197, doi:10.1126/science.1160250, 2008.

Nakahigashi, K., M. Shinohara, K. Mochizuki, T. Yamada, R. Hino, T. Sato, K. Uehira, Y. Ito, Y. Murai, and T. Kanazawa, $P$-wave velocity structure in the southernmost source region of the 2011 Tohoku earthquakes, off the Boso Peninsula, deduced by an ocean bottom seismographic survey, Earth Planets Space, 64, this issue, 1149-1156, 2012.

Nettles, M., G. Ekström, and H. C. Koss, Centroid-moment-tensor analysis of the 2011 off the Pacific coast of Tohoku Earthquake and its larger foreshocks and aftershocks, Earth Planets Space, 63, 519-523, 2011.

Obana, K., G. Fujie, T. Takahashi, Y. Yamamoto, Y. Nakamura, S Kodaira, N. Takahashi, Y. Kaneda, and M. Shinohara, Normalfaulting earthquakes beneath the outer slope of the Japan Trench after the 2011 Tohoku earthquake: Implications for the stress regime in the incoming Pacific plate, Geophys. Res. Lett., 39, L00G24 doi:10.1029/2012GL050399, 2012.

Okada, T., K. Yoshida, S. Ueki, J. Nakajima, N. Uchida, T. Matsuzawa, N. Umino, A. Hasegawa, and Group for the aftershock observations of the 2011 off the Pacific coast of Tohoku Earthquake, Shallow inland earthquakes in NE Japan possibly triggered by the 2011 off the Pacific coast of Tohoku Earthquake, Earth Planets Space, 63, 749-754, 2011.

Ozawa, S., T. Nishimura, H. Suito, T. Kobayashi, M. Tobita, and T. Imakiire, Coseismic and postseismic slip of the 2011 magnitude-9 TohokuOki earthquake, Nature, 475, 373-377, doi:10.1038/nature10227, 2011.

Pollitz, F. F., R. Burgmann, and P. Banerjee, Geodetic slip model of the 2011 M9.0 Tohoku earthquake, Geophys. Res. Lett., 38, L00G08, doi: 10.1029/2011GL048632, 2011.

Reasenberg, P. A. and D. Oppenheimer, FPFIT, FPPLOT and FPPAGE: Fortran computer programs for calculating and displaying earthquake fault-plane solutions, Open-File Report 85-739, Department of the Interior, United States Geological Survey, 1985.

Sakai, S., T. Yamada, M. Shinohara, H. Hagiwara, T. Kanazawa, K. Obana, S. Kodaira, and Y. Kaneda, Urgent aftershock observation of the 2004 off the Kii Peninsula Earthquake using ocean bottom seismometers, Earth Planets Space, 57, 1-6, 2005.

Saito, T., Y. Ito, D. Inazu, and R. Hino, Tsunami source of the 2011 Tohoku-Oki earthquake, Japan: Inversion analysis based on dispersive tsunami simulations, Geophys. Res. Lett., 38, L00G19, doi: 10.1029/2011GL049089, 2011.

Sato, M., T. Ishikawa, N. Ujihara, S. Yoshida, M. Fujita, M. Mochizuki, and A. Asada, Displacement above the hypocenter of the 2011 Tohokuoki earthquake, Science, 332, 1395, doi: 10.1126/science.1207401, 2011.

Shinohara, M., T. Yamada, T. Kanazawa, N. Hirata, Y. Kaneda, T. Takanami, H. Mikada, K. Suyehiro, S. Sakai, T. Watanabe, K. Uehira, Y. Murai, N. Takahashi, M. Nishino, K. Mochizuki, T. Sato, E. Araki, R. Hino, K. Uhira, H. Shiobara, and H. Shimizu, Aftershock observation of the 2003 Tokachi-oki Earthquake by using dense ocean bottom seismometer network, Earth Planets Space, 56, 295-300, 2004.

Shinohara, M., R. Hino, T. Yoshizawa, M. Nishino, T. Sato, and K. Suyehiro, Hypocenter distribution of plate boundary zone off Fukushima, Japan, derived from ocean bottom seismometer data, Earth Planets Space, 57, 93-105, 2005.

Shinohara, M., T. Kanazawa, T. Yamada, K. Nakahigashi, S. Sakai, R. Hino, Y. Murai, A. Yamazaki, K. Obana, Y. Ito, K. Iwakiri, R. Miura, 
Y. Machida, K. Mochizuki, K. Uehira, M. Tahara, A. Kuwano, S. Amamiya, S. Kodaira, T. Takanami, Y. Kaneda, and T. Iwasaki, Precise aftershock distribution of the 2007 Chuetsu-oki Earthquake obtained by using an ocean bottom seismometer network, Earth Planets Space, 60 , 1121-1126, 2008

Shinohara, M., T. Yamada, A. Kuwano, K. Nakahigashi, Y. Machida, K. Mochizuki, T. Kanazawa, T. Takanami, and R. Hino, Geometry of Pacific plate in Kuril-Japan trench zones estimated from earthquake distribution using LT-OBS network and seismic structures by marine surveys, 2009 AGU Fall Meeting, San Francisco (USA), Dec. 18, S53A-1474, 2009.

Shinohara, M., T. Yamada, K. Nakahigashi, S. Sakai, K. Mochizuki, K. Uehira, Y. Ito, R. Azuma, Y. Kaiho, T. No, H. Shiobara, R. Hino, Y. Murai, H. Yakiwara, T. Sato, Y. Machida, T. Shinbo, T. Isse, H. Miyamachi, K. Obana, N. Takahashi, S. Kodaira, Y. Kaneda, K. Hirata, S. Yoshikawa, K. Obara, T. Iwasaki, and N. Hirata, Aftershock observation of the 2011 off the Pacific coast of Tohoku Earthquake by using ocean bottom seismometer network, Earth Planets Space, 63, 835-840, 2011.

Simons, M., S. E. Minson, A. Sladen, F. Ortega, J. L. Jiang, S. E. Owen, L. S. Meng, J. P. Ampuero, S. J. Wei, R. S. Chu, D. V. Helberger, H. Kanamori, E. Heatland, A. W. Moore, and F. H. Webb, The 2011 magnitude 9.0 Tohoku-Oki earthquake: Mosaicking the megathrust from seconds to centuries, Science, 332(6036), 1421-1425, doi:10.1126/science.1206731, 2011.

Suzuki, K., R. Hino, Y. Ito, Y. Yamamoto, S. Suzuki, H. Fujimoto, M. Shinohara, M. Abe, Y. Kawaharada, Y. Hasegawa, and Y. Kaneda, Seismicity near the hypocenter of the 2011 off the Pacific coast of Tohoku earthquake deduced by using ocean bottom seismographic data, Earth Planets Space, 64, this issue, 1125-1135, 2012.

Suzuki, W., S. Aoi, H. Sekiguchi, and T. Kunugi, Rupture process of the 2011 Tohoku-Oki mega-thrust earthquake (M9.0) inverted from strong-motion data, Geophys. Res. Lett., 38, L00G16, doi: 10.1029/2011GL049136, 2011.

Takahashi, N., S. Kodaira, T. Tsuru, J.-O. Park, Y. Kaneda, K. Suyehiro, H. Kinoshita, S. Abe, M. Nishino, and R. Hino, Seismic structure and seismogenesis off Sanriku region, northeastern Japan, Geophys. J. Int., 159, 129-145, 2004.

Umino, N., A. Hasegawa, and T. Matsuzawa, sP depth phase at small epicentral distances and estimated subducting plate boundary, Geophys. J. Int., 120, 356-366, 1995.

Urabe, T. and S. Tsukada, A workstation-assisted processing system for waveform data from microearthquake networks, Abstracts of Spring Meeting of Seismological Society of Japan, 70, 1991 (in Japanese).
Wessel, P. and W. H. F. Smith, Free software helps map and display data, Eos Trans. AGU, 72, 441, 1991

Yagi, Y. and Y. Fukahata, Rupture process of the 2011 Tohoku-oki earthquake and absolute elastic strain release, Geophys. Res. Lett., 38, L19307, doi:10.1029/2011GL048701, 2011.

Yamada, T., M. Shinohara, T. Kanazawa, N. Hirata, Y. Kaneda, T. Takanami, H. Mikada, K. Suyehiro, S. Sakai, T. Watanabe, K. Uehira, Y. Murai, N. Takahashi, M. Nishino, K. Mochizuki, T. Sato, E. Araki, R. Hino, K. Uhira, H. Shiobara, and H. Shimizu, Aftershock distribution of the 2003 Tokachi-oki earthquake derived from high-dense network of ocean bottom seismographs, Zisin 2, 57, 281-290, 2005 (in Japanese with English abstract).

Yamada, T., K. Nakahigashi, A. Kuwano, K. Mochizuki, S. Sakai, M. Shinohara, R. Hino, Y. Murai, T. Takanami, and T. Kanazawa, Spatial distribution of earthquakes off the east coast of Kanto region along the Japan Trench deduced from ocean bottom seismographic observations and their relations with the aftershock sequence of the 2011 off the Pacific coast of Tohoku Earthquake, Earth Planets Space, 63, 841-845, 2011.

Yamanaka, Y. and M. Kikuchi, Asperity map along the subduction zone in northeastern Japan inferred from regional seismic data, J. Geophys. Res., 109, B07307, doi:10.1029/2003JB002683, 2004.

Yamazaki, Y., T. Lay, K. F. Cheung, H. Yue, and H. Kanamori, Modeling near-field tsunami observations to improve finite-fault slip models for the 11 March 2011 Tohoku earthquake, Geophys. Res. Lett., 38, L00G15, doi: 10.1029/2011GL049130, 2011.

Yokota, Y., K. Koketsu, Y. Fujii, K. Satake, S. Sakai, M. Shinohara, and T. Kanazawa, Joint inversion of strong motion, teleseismic, geodetic, and tsunami datasets for the rupture process of the 2011 Tohoku earthquake, Geophys. Res. Lett., 38, L00G21, doi:10.1029/2011GL050098, 2011.

Yoshida, K., A. Hasegawa, T. Okada, T. Iinuma, Y. Ito, and Y. Asano, Stress before and after the 2011 great Tohoku-oki earthquake and induced earthquakes in inland areas of eastern Japan, Geophys. Res. Lett., 39, L03302, doi:10.1029/2011GL049729, 2012.

Yoshida, Y., H. Ueno, D. Muto, and S. Aoki, Source process of the 2011 off the Pacific coast of Tohoku Earthquake with the combination of teleseismic and strong motion data, Earth Planets Space, 63, 565-569, 2011 .

M. Shinohara (e-mail: mshino@eri.u-tokyo.ac.jp), Y. Machida, T. Yamada, K. Nakahigashi, T. Shinbo, K. Mochizuki, Y. Murai, R. Hino, Y. Ito, T. Sato, H. Shiobara, K. Uehira, H. Yakiwara, K. Obana, N. Takahashi, S. Kodaira, K. Hirata, H. Tsushima, and T. Iwasaki 